\title{
Analysis of the accuracy of the sky component calculation in daylighting simulation programs
}

Ignacio Acosta, Carmen M. Muñoz, Paula M. Esquivias, David Moreno and Jaime Navarro

This is an Accepted Manuscript of an article published by Elsevier:

Solar Energy, Volume 119, 2015, Pages 54-67, ISSN 0038-092X, https://doi.org/10.1016/i.solener.2015.06.022

(c) (1) (9) 


\section{Authors' names and affiliations:}

Ignacio Acosta, Instituto Universitario de Arquitectura y Ciencias de la Construcción, Universidad de Sevilla, Lecturer PhD.

Carmen Muñoz, Instituto Universitario de Arquitectura y Ciencias de la Construcción, Universidad de Sevilla, Researcher.

Paula Esquivias, Instituto Universitario de Arquitectura y Ciencias de la Construcción, Universidad de Sevilla, Researcher.

David Moreno, Instituto Universitario de Arquitectura y Ciencias de la Construcción, Universidad de Sevilla, Lecturer PhD.

Jaime Navarro, Instituto Universitario de Arquitectura y Ciencias de la Construcción, Universidad de Sevilla, Professor PhD.

\section{Corresponding Author:}

Ignacio Acosta, University of Seville, Corresponding Author

Tel. number: 0034647550654

Email: iacosta@us.es

\section{Permanent address:}

TEP 130 Research Group, Instituto Universitario de Arquitectura y Ciencias de la Construcción, Universidad de Sevilla, 41012 Sevilla (Spain).

\section{Abstract}

The main aim of this article is to analyze the precision of several lighting simulation programs regularly used in daylighting studies for architecture, following the methodology established in the CIE test cases document. The 3DS Max Design 2014, Daylight Visualizer 2.6, DaySim 3.1 b, Design Builder 3.0, Dialux 4.8, Ecotect Analysis 2011 , Lightscape 3.2 and Relux Pro programs are analyzed. In order to establish the precision for each program, the sky component is measured at different points of study on the floor of a room, taking variable sizes and positions of openings into consideration. The results are contrasted with the analytical calculation of the sky component using Tregenza algorithms and the test cases established by the $\mathrm{CIE}$, considering the models for Traditional and Standard Overcast Sky. Following the analysis of the sky component using the CIE test cases, it is concluded that the 3DS Max Design 2014 and Daylight Visualizer 2.6 programs present a maximum relative difference from the analytical model of close to $10 \%$, while the DaySim 3.1b, 


\section{Analysis of the accuracy of the sky component calculation in daylighting simulation programs}

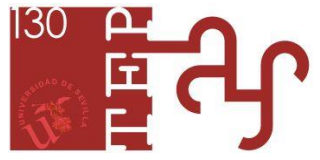

Dialux 4.8 and Lightscape 3.2 programs show a margin of relative error lower than $30 \%$ in all case studies.

Keywords: daylighting, sky component, lighting simulation, overcast sky, test cases

\section{Introduction and objective}

\subsection{State of the art}

Introducing effective daylight strategies has become an essential goal for any sustainable building. However, since it is difficult to evaluate daylight quality and quantity in non-standard spaces using manual methods, the use of daylight simulation has considerably increased as a necessary step towards the accurate evaluation of daylight in buildings in order to help designers or decision makers to choose appropriate architectural and/or technical solutions to achieve a comfortable built environment. Lighting simulation is increasingly becoming a substitute for traditional verification techniques $[1,2,3,4]$.

For the last two decades, the use of computer lighting simulation in building science has been widespread, although the development of natural lighting simulation tools dates back to the 1970s $[3,5,6]$. Computer programs are continuously modified, some of them fall into disuse and others supersede them or update their algorithms to guarantee greater accuracy [4].

Given the great number of simulation models available, numerous evaluations have been published. These can be divided into two groups: comparisons based on replicating a built reality (scale models or reality), and comparisons in controlled laboratory settings $[3,4,7]$, although it is difficult to compare the results obtained using each individual method. In addition, lighting simulation tool comparisons have been widely published to help lighting designers choose the most suitable program, and standardized comparison methods have been developed $[8,9]$. These comparison methods are usually carried out by simulation experts $[1,10]$, whose knowledge about daylight and the underlying algorithms is much higher than self-taught new practitioners.

The growing use and interest in daylight simulation tools can be attributed to building standards and, most of all, to Green building rating systems [1]. A number of surveys were carried out in the past regarding the use of building simulation tolos during building design. In 1994, almost $77 \%$ of participants in a survey used both computers and physical models for their professional practice. By 2004, participants who used no daylight prediction software had dropped to 21\% [11]. This percentage may be reduced even further as architectural and engineering students become increasingly familiar with computer modelling throughout their education [3]. 


\section{Analysis of the accuracy of the sky component calculation in daylighting simulation programs}

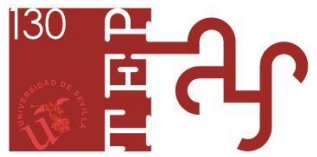

Most building design practitioners and students who are currently building three dimensional CAD models are using their models to visualize their designs for qualitative analysis and client presentation purposes [9]. On occasion, newcomers do not have expertise in daylighting, while novice users are confident that their results do not differ drastically from those of expert users, although some studies have reported the discrepancy between non-expert and expert user results [1].

This paper presents a study of the accuracy of several simulation programs, some of them specifically developed for daylighting analysis and others for architectural design, artificial lighting, energy analysis or whole-building conceptual design, widely used in practice, and incorporating daylighting analysis modules exclusively on the calculation of the sky component, using the corresponding CIE Test Cases. It also presents the discrepancy between the default value results given by these programs, mainly used by novice users, and the validated value results given by expert users for validation reports.

\subsection{Daylighting simulation and tools}

Modern physical models explaining light transport in all types of media are too complex for computer calculations and image generation [3]. A simplified model of geometrical optics and energy conservation, from which physical formulas are established, is used instead. However, differences between measurements and simulations in specific modelling contexts might be accounted for by these simplifications, particularly when diffusing or refracting media are involved [3].

A large number of different program interfaces is currently used, but the underlying simulation algorithms concentrate on a limited number of approaches. These can be classified into three types: direct calculations, view-dependent algorithms and scene-dependent algorithms. The two most popular in use today are ray-tracing and radiosity, although other scene-dependent algorithms, known as integrative approaches (such as the photon map), have been developed $[3,4,10,11]$.

The inclusion of daylight analysis in energy tools is not new $[6,12]$; some studies have reported how energy and daylight analysis could be coupled $[13,14]$. The use of energy simulation programs for daylight analysis is of growing interest as one model could give different performance building aspect results, thus saving time on building different models using different programs.

The international implementation of green building standards such as LEED or BREEAM, which establish many quantifiable performance requirements for the guidance and control of architectural design, is encouraging performance-driven design, bringing more rational thinking and scientific analysis, such as Daylighting Analysis, into the field of architectural design [5]. 


\section{Analysis of the accuracy of the sky component calculation in daylighting simulation programs}

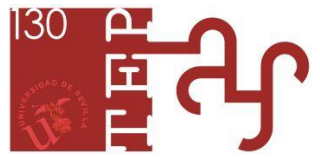

Performance-driven architectural design emphasizes an integrated and comprehensive optimization of various quantifiable performances of buildings. Compared with conventional architectural design methodology which focuses on space form, performance-driven design takes a holistic view of ecological and environmental performance of buildings while ensuring that the functions and aesthetics of the design are not overlooked [5].

\subsection{Software validation tests to assess daylight accuracy}

A number of computer software programs exists which model the distribution of light inside a building. A literature search revealed a number of papers comparing various software packages and computation methods. Experience has shown that results for the same room, obtained from different daylight simulation programs, can give different results. This may be due to restrictions in the program itself and/or to the skills of those setting up the models. It is therefore important for results to be acceptable and for users to know the limitations of the tools used [10].

Current and future use of lighting simulation programs depend largely on their accuracy as demonstrated in published validation studies [15]. Most of the existing literature on lighting program validation is limited to two categories: comparisons between simulation results and experimental measurements in scale models or reality, and comparisons between simulation results from different lighting programs $[3,7]$. When the calculations are compared with experimental results (in scale models or real cases), the main problem is the large number of error sources [15].

A literature review shows a number of studies comparing lighting simulation results with measurements under real conditions in scale models or inside a room $[3,4]$. Ubbelohde and Humman [16] compared four program results, including Radiance, with measurements carried out on a building in San Francisco. Ashmore and Richens [17] also studied four simulation programs and compared simulation results with a scale model under two artificial overcast skies. Similar studies were conducted by Acosta et al. [18], Galasiu and Atif [19] and Ng [20]. Others were one-to-one, as the case of multiple articles comparing simulation results with a program with measurements in a real case $[21,22,23]$.

Validations under controlled laboratory settings reduce uncertainty and are of use to developers in testing algorithms. Simulation results are compared with analytical results based on theoretical laws [7]. This is the case of Khodulev and Kopylov [24] who compared the Lightscape, Radiance and Specter (from the developers of Inspirer) tools against theoretical results. This approach identified the capabilities and limitations of a program, and therefore its errors, when using it outside its area of application. 


\section{Analysis of the accuracy of the sky component calculation in daylighting simulation programs}

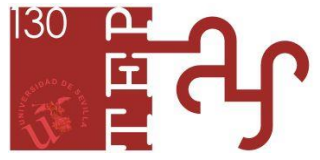

Nevertheless, there have been some data sets produced in one-to-one scale testing cells where the experimental scenarios are described as accurately as possible. Mardaljevic successfully validated Radiance for a set of clear and overcast sky measurements in a room with three fenestration systems. This work was extended to validate radiance through the BRE dataset of test conditions [25].

In 1999, the IEA SHC Task 21 conducted a valuable study in the domain of lighting program validation, where a set of experimental validation datasets was created and compared to a number of existing tools [26]. The work of Task 21 was continued by Maamari and Fontoynont [7] who developed a set of test scenarios which served as the basis for the CIE test cases [8].

In a continuation of this work, and to broaden the domain of lighting propagation covered by these types of reliable datasets, a set of simple test cases has been defined or collected within the activities of the CIE Technical Committee 3.33 [8] and Subtask C of the IEA SHC Task 31 [2].

The validation approach proposed through the CIE test cases in 2006 is based on the concept of testing the different aspects of the lighting simulation separately. These cases are mainly based on theoretical scenarios with analytically calculated reference data, thus avoiding uncertainties.

\subsection{Objective}

The main aim of this research is to determine the precision of the lighting software programs usually employed in the study of daylighting in architecture. Unlike previous studies, in order to carry out the assessment of the different types of software the sky component in a room will be studied, considering different sizes and positions of openings, so that all the tests are compared with the analytical calculation of the sky component with Tregenza algorithms [27] and the test cases established by the CIE [8]. Thus, the analysis of lighting software precision is carried out analytically and objectively, without the variability of results characteristic of empirical validations.

The programs evaluated in this study are 3DS Max Design 2014, Daylight Visualizer 2.6, DaySim 3.1b, Design Builder 3.0, Dialux 4.8, Ecotect Analysis 2011, Lightscape 3.2 and Relux Pro. Given that each type of software uses a different interpretation of sky luminance, the contrasting analytical calculation is carried out according to the overcast sky model used by each lighting software, which may be a Traditional or Standard Overcast Sky. Both sky models are validated by the CIE and represent similar luminance values [28].

\section{Description of Methodology for Calculation}

\subsection{Choosing the calculation conditions}




\section{Analysis of the accuracy of the sky component calculation in daylighting simulation programs}

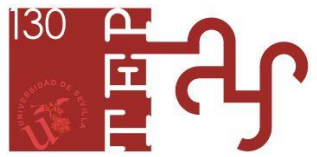

Given that each type of software uses a different interpretation of sky luminance, the evaluation of precision is carried out using the overcast sky model for each lighting software. Therefore, calculation conditions describe two models of overcast sky: Traditional and Standard.

\subsubsection{Traditional Overcast Sky}

By definition, the calculation of daylight factor components is carried out considering an unobstructed sky of assumed or known illuminance distribution, excluding direct sunlight. The definition of traditional overcast sky is used to calculate the sky component.

The overcast sky model, used in the methodology, is that defined by Moon-Spencer [29], where the luminance values are distributed according to the following:

$$
L_{\theta}=L_{z} \cdot(1+2 \sin \theta) / 3
$$

where " $L z$ " is the luminance at the zenith of the sky vault and " $\theta$ " the projection angle. This implies that the lowest luminance value in an overcast sky vault occurs on the horizon, and is equivalent to a third of the maximum luminance at the zenith:

$$
\mathrm{L}_{0}=\mathrm{L}_{z} / 3
$$

The formulation established by Moon-Spencer corresponds to the definition of overcast sky accepted by the CIE [28], which is known as traditional overcast sky.

\subsubsection{Standard Overcast Sky}

The definition of Standard Overcast Sky was developed by Perez et al. [30] and is accepted by the CIE [28]. According to this definition the ratio of the luminance, La, of an arbitrary sky element to the zenith luminance, $L z$, is:

$$
\mathrm{La} / \mathrm{Lz}=(f(\mathrm{X}) \cdot \phi(Z)) /(f(\mathrm{Zs}) \cdot \phi(0))
$$

where:

$f(x)=1$

$f(Z s)=1$

$\phi(Z)=1+4 \cdot \exp (-0.7 / \cos Z)$

$\phi(0)=1+4 \cdot \exp (-0.7)$.

The Standard Overcast Sky model determines a sky luminance that is very similar to that of the Traditional Overcast Sky, with an ascending grading of the luminance towards the zenith, while azimuthal uniformity is maintained. 
The luminance values of both sky models are very similar at the zenith, although they tend to differ in the horizon [28]. Therefore, it is necessary to use the sky definition for each lighting software in order to prevent margins of error.

\subsection{Calculation model}

Two calculation models were established to assess the sky component in the different calculation models: the room with a roof opening and the room with a façade opening. In all cases the calculation models are based on the methodology established by CIE test cases [8].

The sky component is assessed over a series of study points on the central axis of the floorplan of each model, placed $0.50 \mathrm{~m}$ apart, as can be seen in Figures 1 and 2 .

\subsubsection{Calculation model with unglazed roof opening}

The geometry used for this test case is a rectangular room of $4 \mathrm{~m} \times 4 \mathrm{~m} \times 3 \mathrm{~m}$ with a $1 \mathrm{~m} \times 1 \mathrm{~m}$ or $4 \mathrm{~m} \times 4 \mathrm{~m}$ roof opening at the centre of the ceiling (Figure 1). The thickness of the roof is not taken into consideration although an external envelope is recommended to avoid possible light leakage. The internal surfaces are ideal diffuse reflectors with $0 \%$ reflectance, meaning that in the absence of reflected components, the incident illuminance on the inner surfaces of the model only depends on the sky component. The measurement floor points are positioned as shown in Figure 1.

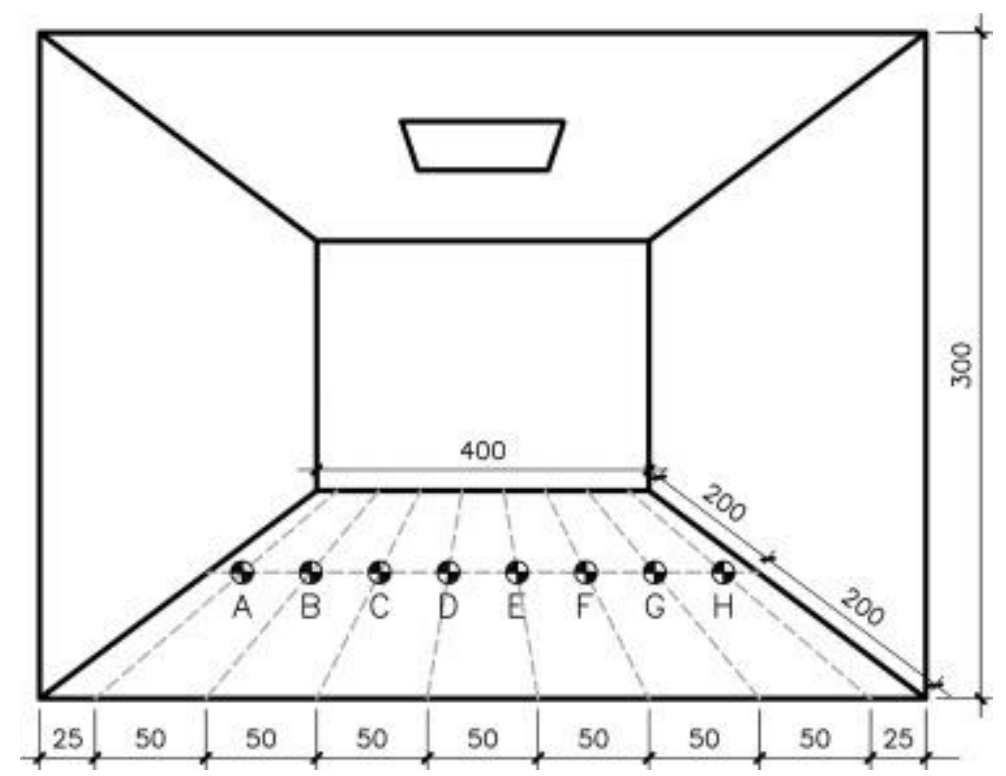

Figure 1: Geometry and measurement points of the calculation models.

\subsubsection{Calculation model with unglazed façade opening}

The second model uses a room identical to the previous one, with a square floorplan with $4 \mathrm{~m}$ sides and a $3 \mathrm{~m}$ height. The geometry used is a rectangular room of $4 \mathrm{~m} \times 4 \mathrm{~m} \times 3 \mathrm{~m}$ with a south façade 
opening of $2 \mathrm{~m} \times 1 \mathrm{~m}$ or $4 \mathrm{~m} \times 3 \mathrm{~m}$ (Figure 2). The wall thickness is not taken into consideration and the interior surfaces have a reflectance of $0 \%$ to avoid the internal reflected component. The measurement floor points are positioned as shown in Figure 2.

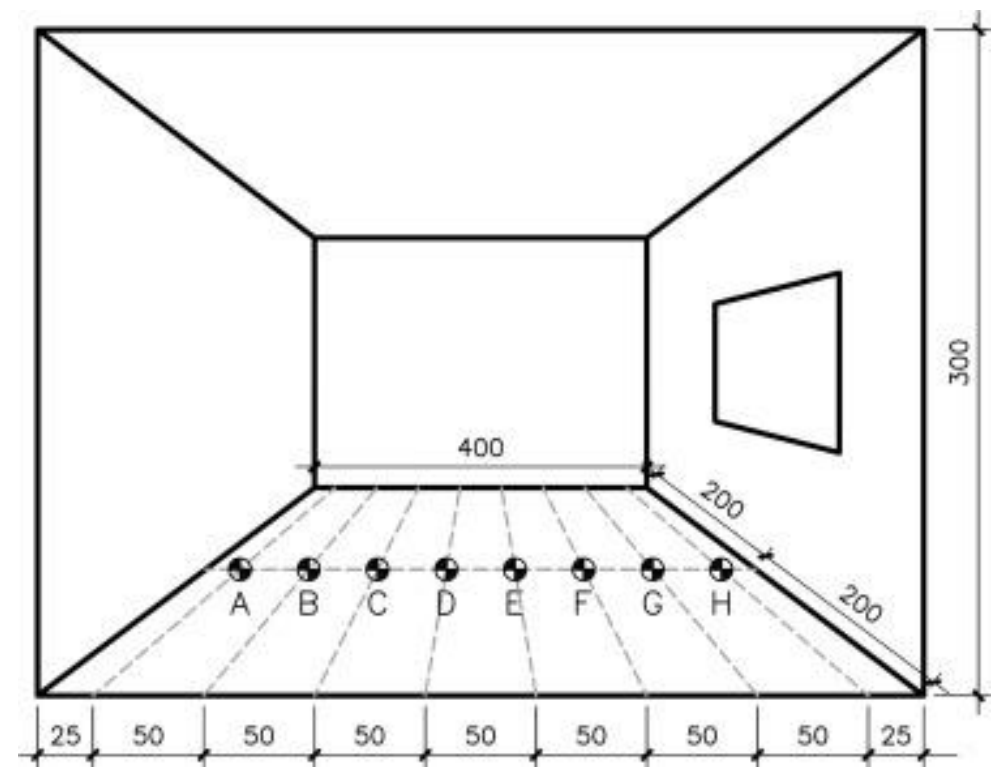

Figure 2: Geometry and measurement points of the calculation models.

\subsection{Analytical reference}

The sky component takes the direct illuminance received at the interior of the room through the aperture from the visible zone of the sky into consideration. This illuminance varies for a given point according to the luminance distribution of the sky and the portion of the sky that is visible to the point. This luminance distribution is usually proposed as a standardized sky model. For the CIE general sky types, the direct component can be calculated analytically for the traditional overcast sky, using Tregenza algorithms [27].

The proposed analytical solution for the standard overcast sky was calculated with a computer program developed for this purpose (Skylux) [8], and validated through comparison with the analytical solutions for traditional overcast sky. The procedure used subdivides the surface into thousands of sub-surfaces and calculates the average luminance of the sky zone visible through each sub-surface from a given measurement point. The direct illuminance is then calculated by integrating the contribution of each sub-surface. The difference between the program results and the analytical solution is less than $0.1 \%$.

\subsubsection{Analytical reference to model with unglazed roof opening}

The values of the sky component on the established points of study and obtained using Tregenza algorithms [27] and the CIE test cases [8] are shown in Table 1, depending on the sky model used. 
Analysis of the accuracy of the sky component calculation in daylighting simulation programs

\begin{tabular}{lllllllllll}
\hline \multirow{2}{*}{ Sky model } & $\begin{array}{l}\text { Type } \\
\text { of Sky }\end{array}$ & $\begin{array}{l}\text { Roof } \\
\text { opening }\end{array}$ & A & B & C & D & E & F & G & H \\
\hline \multirow{2}{*}{ TRADITIONAL } & \multirow{2}{*}{ MyS } & $1 \times 1 \mathrm{~m}$. & 2.29 & 3.07 & 3.82 & 4.29 & 4.29 & 3.82 & 3.07 & 2.29 \\
\cline { 2 - 11 } & $4 \times 4 \mathrm{~m}$. & 31.36 & 36.76 & 40.71 & 42.75 & 42.75 & 40.71 & 36.76 & 31.36 \\
\hline \multirow{2}{*}{ STANDARD } & \multirow{2}{*}{ Perez } & $1 \times 1 \mathrm{~m}$. & 2.33 & 3.11 & 3.84 & 4.29 & 4.29 & 3.84 & 3.11 & 2.33 \\
\cline { 2 - 10 } & & $4 \times 4 \mathrm{~m}$. & 31.87 & 37.3 & 41.27 & 43.35 & 43.35 & 41.27 & 37.3 & 31.87 \\
\hline
\end{tabular}

Table 1: Calculation of the sky component at the study points of the models with roof opening according to analytical calculation.

\subsubsection{Analytical reference to model with unglazed façade opening}

The values of the sky component over the floorplan, obtained using Tregenza algorithms [27] and the CIE test cases [8], are shown in Table 2, depending on the sky model used.

\begin{tabular}{lllllllllll}
\hline \multirow{2}{*}{ Sky model } & $\begin{array}{l}\text { Type } \\
\text { of Sky }\end{array}$ & $\begin{array}{l}\text { Façade } \\
\text { opening }\end{array}$ & $\mathrm{A}$ & $\mathrm{B}$ & $\mathrm{C}$ & $\mathrm{D}$ & $\mathrm{E}$ & $\mathrm{F}$ & $\mathrm{G}$ & $\mathrm{H}$ \\
\hline \multirow{2}{*}{ TRADITIONAL } & \multirow{2}{*}{ MyS } & $2 \times 1 \mathrm{~m}$. & 0.95 & 1.38 & 2.07 & 3.19 & 4.97 & 7.42 & 9.11 & 5.04 \\
\cline { 2 - 12 } & $4 \times 3 \mathrm{~m}$. & 4.5 & 6.15 & 8.53 & 12 & 16.97 & 23.91 & 33.08 & 44.43 \\
\hline \multirow{2}{*}{ STANDARD } & \multirow{2}{*}{ Perez } & $2 \times 1 \mathrm{~m}$. & 0.87 & 1.31 & 2.02 & 3.2 & 5.07 & 7.64 & 9.33 & 5.09 \\
\cline { 2 - 11 } & $4 \times 3 \mathrm{~m}$. & 4.27 & 5.92 & 8.33 & 11.82 & 16.84 & 23.83 & 33.05 & 44.06 \\
\hline
\end{tabular}

Table 2: Calculation of the sky component at the study points of the models with façade opening according to analytical calculation.

\subsection{Calculation programs under study}

After analyzing the sky component, an accurate analysis is carried out of the most frequent lighting software, both in research and architecture design. As stated in the aims, assessments are carried out for 3DS Max Design 2014, Daylight Visualizer 2.6, DaySim 3.1b, Design Builder 3.0, Dialux 4.8, Ecotect Analysis 2011 , Lightscape 3.2 and Relux Pro software. Parameters have been provided for all the programs that allow an optimum precision of the results obtained, considering a processing time of calculation of under an hour per model. The calculation parameters for each simulation program are shown below in Tables 3 to 10 .

3DS Max Design is based on ExposureTM technology, a lighting analysis module that includes a 'shader' of the Perez sky model and uses the mental ray ${ }^{\circledR}$ raytracer for the global illumination calculation. When using the same input parameters 3DS Max Design uses the same sky luminance distribution as Daysim.

\begin{tabular}{ll}
\hline 3DS Max Design 2014 & \\
\hline Calculation & Ray-tracing \\
\hline Sky Conditions & Standard Overcast Sky \\
\hline Daylight Parameters & \\
\hline Sunlight & Inactive \\
\hline Skylight & Active mr Sky \\
\hline
\end{tabular}




\begin{tabular}{lll}
\hline Sky Parameters & \multicolumn{2}{l}{ On (Multiplier =1) } \\
\hline Sky Model & CIE & \\
\hline \multirow{3}{*}{ Sky Advanced Parameters } & Horizon & $\mathrm{H}=0 ; \mathrm{B}=0,1$ \\
\cline { 2 - 3 } & Non-Physical Tuning (1) & $\mathrm{R} / \mathrm{B}=0,0$ \\
\cline { 2 - 3 } & Non-Physical Tuning (2) & $\mathrm{S}=1$ \\
\cline { 2 - 3 } & Aerial Perspective & $\mathrm{Off}$ \\
\hline \multirow{3}{*}{ Sky: ClE Parameters } & Diffuse Horiz & $10000 \mathrm{~lx}$ \\
\cline { 2 - 3 } & Direct Normal Iluminance & Olx \\
\cline { 2 - 3 } & Sky & Overcast \\
\hline Lighting Analysis Assistant & & \\
\hline Final Gather & & Enable \\
\hline FG Precision Presets & & Very High \\
\hline Initial FG Point Density & & 10000 \\
\hline Rays per FG Point & 100 \\
\hline Interpolate Over Num. FG Points & 0 \\
\hline Diffuse Bounces & 1 \\
\hline Weight &
\end{tabular}

Table 3: 3DS Max Design 2014 simulation parameters.

Daylight Visualizer is a software tool dedicated to daylighting design and analysis, funded by Velux. It simulates daylight transport in buildings, aiding professionals by predicting and documenting daylight levels and the appearance of a space prior to the execution of the building design. In addition to photorealistic rendering, the simulation outputs include luminance, illuminance and daylight factor maps. It can calculate daylight factors for all 15 sky types defined in CIE Standard General Sky [28].

\begin{tabular}{ll}
\hline \multicolumn{2}{l}{ Daylight Visualizer 2.6 } \\
\hline Calculation & Ray-tracing \\
\hline Sky Conditions & Standard Overcast Sky \\
\hline Ambient & On \\
\hline Trace level & 8 \\
\hline Ambient trace level & 8 \\
\hline Ambient precision & 1 \\
\hline Ambient complexity & 10 \\
\hline Ambient feature size & 1 \\
\hline
\end{tabular}

Table 4: Daylight Visualizer 2.6 simulation parameters.

Daysim is a validated Radiance-based daylighting analysis tool that uses a daylight coefficient approach combined with the Perez all weather sky model to predict the amount of daylight in and around buildings, based on direct normal and diffuse horizontal irradiances taken from a climate file. Daysim was developed for a more efficient calculation of illuminance or luminance time series under varying sky conditions than that provided by Radiance in its original form. Daysim results tend to be very similar to Radiance Classic results especially under overcast sky conditions. Under sunny sky conditions Daysim simulation results can diverge from Radiance since Daysim interpolates direct 
Analysis of the accuracy of the sky component calculation in daylighting simulation programs

solar contributions for specific sky conditions from four neighbouring, representative sky conditions [9].

\begin{tabular}{lll}
\hline DaySim 3.1b & \multicolumn{2}{l}{ Ray-tracing } \\
\hline Calculation & Standard Overcast Sky & \\
\hline Sky Conditions & Ambient Bounces & 7 \\
\cline { 2 - 3 } & Ambient Divisions & 1500 \\
\cline { 2 - 3 } & Ambient Super-samples & 100 \\
\cline { 2 - 3 } & Ambient Resolution & 300 \\
\cline { 2 - 3 } & Ambient Accuracy & 0.05 \\
\cline { 2 - 3 } Radiance Simulation Parameter & Limit Reflection & 10 \\
\cline { 2 - 3 } & Specular Threshold & 0.0000 \\
\cline { 2 - 3 } & Specular Jitter & 1.0000 \\
\cline { 2 - 3 } & Limit Weight & 0.0040 \\
\cline { 2 - 3 } & Direct Jitter & 0.0000 \\
\cline { 2 - 3 } & Direct Sampling & 0.2000 \\
\cline { 2 - 3 } & Direct Relays & 2 \\
\cline { 2 - 3 } & Direct Pretest Density & 512 \\
\hline
\end{tabular}

Table 5: DaySim 3.16 simulation parameters.

Design Builder is a comprehensive user interface to the EnergyPlus dynamic thermal simulation engine for checking building energy, carbon, lighting and comfort performance. The EnergyPlus program is an energy analysis and thermal load simulation program developed by the U.S. Department of Energy. It is based on a combination of BLAST, which provides the heat balance method, and DOE-2, whose daylighting calculation is derived to the EnergyPlus daylighting calculation $[12,14]$. The daylighting algorithms of EnergyPlus are based on radiosity and split-flux methods.

\begin{tabular}{ll}
\hline Design Builder 3.0 & \\
\hline Calculation & Ray-tracing \\
\hline Sky Conditions & Standard Overcast Sky \\
\hline Calculation options & 1 Map \\
\hline Report type & Accurate \\
\hline Detail template & 0 \\
\hline Working plane height $(\mathrm{m})$ & 0 \\
\hline Margin & \\
\hline Advanced options & 0.250 \\
\hline Minimum mesh spacing & 0.250 \\
\hline Maximum mesh spacing & 5 \\
\hline Ambient Bounces & 0.2 \\
\hline Ambient Accuracy & 512 \\
\hline Ambient Resolution & 2048 \\
\hline Ambient Divisions & 1024 \\
\hline Number of ambient super samples
\end{tabular}

Table 6: Design Builder 3.0 simulation parameters. 


\section{Analysis of the accuracy of the sky component calculation in daylighting simulation programs}

Dialux calculates electric light, daylight and energy performance of electric light. The program is oriented towards the European market, and is widely used for the calculation of indoor and outdoor electric lighting systems. It follows different national standard lighting calculations. Dialux 4 is based on the RadiCal module, which calculates the light exchange between light sources and other sources (direct lighting) and also the light exchange between illuminated surfaces (indirect lighting) using the radiosity method with adaptive meshing.

\begin{tabular}{ll}
\hline Dialux 4.8 & \\
\hline Calculation & Radiosity \\
\hline Sky Conditions & Traditional Overcast Sky \\
\hline Calculation options & Very accurate \\
\hline Calculation procedures & Automatic \\
\hline Daylight Factors & Calculate Daylight Factors \\
\hline
\end{tabular}

Table 7: Dialux 4.8 simulation parameters.

Ecotect is a graphical building and environmental analysis tool. Ecotect Analysis offers a wide range of simulation and building energy analysis functions. These simulations and analyses include the energy performance of buildings, thermal simulations, solar radiation, daylight levels and shadow diagrams [10].

\begin{tabular}{ll}
\hline Ecotect Analysis 2011 & \\
\hline Calculation & Split-flux \\
\hline Sky Conditions & Traditional Overcast Sky \\
\hline Number of spherical rays per sample point & 16384 \\
\hline Design Sky Illuminance & 8080 \\
\hline Window cleanliness & 1 \\
\hline Room-averaged window areas & Active \\
\hline Which aspect is more important & Increased Accuracy \\
\hline
\end{tabular}

Table 8: Ecotect Analysis 2011 simulation parameters.

Lightscape is a lighting and visualization application that uses both radiosity and ray-tracing algorithms where only the radiosity solution is considered for the quantitative results. The radiosity algorithm applied uses progressive refinement and adaptive meshing methods.

\begin{tabular}{|c|c|c|}
\hline \multicolumn{3}{|l|}{ Lightscape 3.2} \\
\hline Calculation & \multicolumn{2}{|l|}{ Radiosity } \\
\hline Sky Conditions & \multicolumn{2}{|l|}{ Traditional Overcast Sky } \\
\hline \multirow{2}{*}{ Mesh Spacing } & Min & $0.10 \mathrm{~m}$ \\
\hline & Max & $0.20 \mathrm{~m}$ \\
\hline \multicolumn{2}{|c|}{ Subdivision Contrast Threshold } & 0.40 \\
\hline \multicolumn{2}{|c|}{ Skylight Accuracy } & 0.60 \\
\hline \multirow{6}{*}{ Source } & Direct Source & 0.20 \\
\hline & Subdivision Accuracy & 0.70 \\
\hline & \multirow{2}{*}{ Indirect Source $\frac{\text { Min }}{\text { Subdivision Accuracy }}$} & 0.40 \\
\hline & & 0.70 \\
\hline & Shadow Grid Size & Five \\
\hline & Length & 0.0005 \\
\hline
\end{tabular}




\begin{tabular}{lll}
\hline Tolerances & Ray Offset & 0.001 \\
\cline { 2 - 3 } & Initialization Min Area & 0.01 \\
\hline
\end{tabular}

Table 9: Lightscape 3.2 simulation parameters.

ReluxPro is a lighting program used for both artificial lighting and daylighting simulations. Within ReluxPro, all three paradigms (Radiosity, Raytracing and Raster graphics) are employed, radiosity is used in the basic calculation engine, the Raster graphics are the base of the interactive OpenGL view and edit module, and finally there is a separate raytracing feature for rendering.

\begin{tabular}{lll}
\hline Relux Pro & \\
\hline Calculation & Radiosity & \\
\hline Sky Conditions & Traditional Overcast Sky & \\
\hline \multirow{2}{*}{ Room area Diffuse Material } & Surface finish Specularity & $0 \%$ \\
\cline { 2 - 3 } & Surface finish Roughness & $0 \%$ \\
\hline \multirow{2}{*}{ Windows } & Attenuation factor partitioning & 1 \\
\cline { 2 - 3 } & Pollution Attenuation factor & 1 \\
\cline { 2 - 3 } & Default material Glass & $100 \%$ \\
\hline \multirow{4}{*}{ Calculation } & Precision & low indirect fraction \\
\cline { 2 - 3 } & Raster spacing & 0.25 \\
\cline { 2 - 3 } & Recommendation with & Fine \\
\hline
\end{tabular}

Table 10: Relux Pro simulation parameters.

\section{Calculation}

\subsection{Lighting software results in the model with unglazed roof opening}

After establishing the calculation model and the analytical results to be used as reference to assess the precision of the lighting software, simulations are carried out that are supported on the calculation parameters established in point 2.4. The results obtained from each type of software for the model with a roof opening are shown in Table 11.

\begin{tabular}{|c|c|c|c|c|c|c|c|c|c|c|}
\hline $\begin{array}{l}\text { Lighting } \\
\text { Software }\end{array}$ & $\begin{array}{l}\text { Type } \\
\text { of Sky }\end{array}$ & $\begin{array}{l}\text { Roof } \\
\text { opening }\end{array}$ & $A$ & $B$ & C & $\mathrm{D}$ & $E$ & $\mathrm{~F}$ & G & $\mathrm{H}$ \\
\hline \multirow{2}{*}{$\begin{array}{l}\text { 3DS Max } \\
\text { Design } \\
2014\end{array}$} & \multirow[b]{2}{*}{ Perez } & $1 \times 1 \mathrm{~m}$. & 2.28 & 2.97 & 3.94 & 4.54 & 4.50 & 3.90 & 3.19 & 2.37 \\
\hline & & $4 \times 4 \mathrm{~m}$. & 32.02 & 37.44 & 41.32 & 43.52 & 43.78 & 41.57 & 37.32 & 31.96 \\
\hline \multirow{2}{*}{$\begin{array}{l}\text { Daylight } \\
\text { Visualizer } \\
2.6\end{array}$} & \multirow[b]{2}{*}{ Perez } & $1 \times 1 \mathrm{~m}$. & 2.35 & 3.10 & 3.85 & 4.25 & 4.30 & 3.90 & 3.10 & 2.35 \\
\hline & & $4 \times 4 \mathrm{~m}$ & 31.85 & 37.30 & 41.30 & 43.40 & 43.40 & 41.25 & 37.30 & 31.90 \\
\hline \multirow{2}{*}{$\begin{array}{l}\text { DaySim } \\
3.1 \mathrm{~b}\end{array}$} & \multirow{2}{*}{ Perez } & $1 \times 1 \mathrm{~m}$. & 2.30 & 3.13 & 4.38 & 4.31 & 4.60 & 4.06 & 3.31 & 2.35 \\
\hline & & $4 \times 4 \mathrm{~m}$. & 32.25 & 37.85 & 42.23 & 44.44 & 44.34 & 42.32 & 38.12 & 32.14 \\
\hline \multirow{2}{*}{$\begin{array}{l}\text { Design } \\
\text { Builder } 3.0\end{array}$} & \multirow{2}{*}{ Perez } & $1 \times 1 \mathrm{~m}$. & 2.57 & 2.84 & 3.82 & 4.10 & 3.90 & 4.00 & 2.90 & 2.50 \\
\hline & & $4 \times 4 \mathrm{~m}$. & 39.77 & 42.22 & 46.78 & 49.07 & 49.07 & 46.74 & 42.25 & 39.77 \\
\hline \multirow{3}{*}{ Dialux 4.8} & \multirow{2}{*}{ MyS } & $1 \times 1 \mathrm{~m}$. & 2.32 & 2.87 & 3.68 & 4.11 & 4.13 & 3.66 & 2.87 & 2.32 \\
\hline & & $4 \times 4 \mathrm{~m}$. & 31.00 & 36.00 & 40.00 & 42.00 & 42.00 & 40.00 & 36.00 & 31.00 \\
\hline & MyS & $1 \times 1 \mathrm{~m}$. & 2.64 & 3.90 & 6.30 & 8.88 & 9.03 & 6.20 & 3.95 & 2.74 \\
\hline
\end{tabular}


Analysis of the accuracy of the sky component calculation in daylighting simulation programs

\begin{tabular}{|c|c|c|c|c|c|c|c|c|c|c|}
\hline $\begin{array}{l}\text { Ecotect } \\
\text { Analysis } \\
2011\end{array}$ & & $4 \times 4 \mathrm{~m}$. & 37.60 & 46.07 & 50.93 & 52.78 & 53.08 & 50.55 & 45.42 & 37.89 \\
\hline \multirow{2}{*}{$\begin{array}{l}\text { Lightscape } \\
3.2\end{array}$} & \multirow{2}{*}{ MyS } & $1 \times 1 \mathrm{~m}$. & 2.14 & 2.69 & 3.34 & 3.64 & 3.62 & 3.33 & 2.66 & 2.18 \\
\hline & & $4 \times 4 \mathrm{~m}$. & 29.44 & 33.88 & 37.22 & 39.17 & 39.17 & 37.44 & 33.86 & 30.00 \\
\hline \multirow{2}{*}{ Relux Pro } & \multirow{2}{*}{ MyS } & $1 \times 1 \mathrm{~m}$. & 1.96 & 2.76 & 3.41 & 3.81 & 3.81 & 3.41 & 2.76 & 1.96 \\
\hline & & $4 \times 4 \mathrm{~m}$. & 30.07 & 34.75 & 38.13 & 39.98 & 39.98 & 38.13 & 34.75 & 30.07 \\
\hline
\end{tabular}

Table 11: Calculation of the sky component at the study points of the models with unglazed roof opening according to lighting simulation programs.

\subsection{Lighting software results in the model with unglazed façade opening}

Just as with the previous study, the results obtained from each type of lighting software for the model with façade opening are shown in Table 12.

\begin{tabular}{|c|c|c|c|c|c|c|c|c|c|c|}
\hline $\begin{array}{l}\text { Lighting } \\
\text { Software }\end{array}$ & $\begin{array}{l}\text { Type } \\
\text { of Sky }\end{array}$ & $\begin{array}{l}\text { Façade } \\
\text { opening }\end{array}$ & $A$ & B & C & $\mathrm{D}$ & $E$ & $\mathrm{~F}$ & G & $\mathrm{H}$ \\
\hline \multirow{2}{*}{$\begin{array}{l}\text { 3DS Max } \\
\text { Design } 2014\end{array}$} & \multirow{2}{*}{ Perez } & $2 \times 1 \mathrm{~m}$. & 0.94 & 1.30 & 2.04 & 3.15 & 4.96 & 7.67 & 9.68 & 5.70 \\
\hline & & $4 \times 3 \mathrm{~m}$ & 4.41 & 5.92 & 8.28 & 11.82 & 16.75 & 23.53 & 32.91 & 43.97 \\
\hline \multirow{2}{*}{$\begin{array}{l}\text { Daylight } \\
\text { Visualizer } 2.6\end{array}$} & \multirow{2}{*}{ Perez } & $2 \times 1 \mathrm{~m}$. & 0.90 & 1.30 & 2.00 & 3.20 & 5.10 & 7.60 & 9.35 & 5.10 \\
\hline & & $4 \times 3 \mathrm{~m}$. & 4.25 & 5.90 & 8.35 & 11.80 & 16.85 & 23.85 & 33.00 & 44.10 \\
\hline \multirow{2}{*}{ DaySim $3.1 \mathrm{~b}$} & \multirow{2}{*}{ Perez } & $2 \times 1 \mathrm{~m}$. & 0.88 & 1.21 & 2.02 & 3.21 & 5.08 & 7.64 & 10.29 & 6.54 \\
\hline & & $4 \times 3 \mathrm{~m}$. & 4.20 & 5.73 & 8.13 & 11.56 & 16.34 & 23.43 & 32.49 & 44.29 \\
\hline \multirow{2}{*}{$\begin{array}{l}\text { Design } \\
\text { Builder } 3.0\end{array}$} & \multirow{2}{*}{ Perez } & $2 \times 1 \mathrm{~m}$. & 1.40 & 1.70 & 2.30 & 3.42 & 5.35 & 7.78 & 9.50 & 6.70 \\
\hline & & $4 \times 3 \mathrm{~m}$. & 7.14 & 8.32 & 10.67 & 13.02 & 20.07 & 26.34 & 37.32 & 46.60 \\
\hline \multirow{2}{*}{ Dialux 4.8} & \multirow{2}{*}{ MyS } & $2 \times 1 \mathrm{~m}$. & 0.91 & 1.32 & 2.01 & 2.99 & 4.59 & 6.85 & 8.15 & 3.84 \\
\hline & & $4 \times 3 \mathrm{~m}$. & 4.35 & 6.09 & 8.47 & 12.00 & 16.00 & 23.00 & 32.00 & 43.00 \\
\hline \multirow{2}{*}{$\begin{array}{l}\text { Ecotect } \\
\text { Analysis } \\
2011\end{array}$} & \multirow{2}{*}{ MyS } & $2 \times 1 \mathrm{~m}$. & 1.09 & 1.47 & 1.84 & 2.96 & 4.23 & 6.87 & 8.75 & 7.68 \\
\hline & & $4 \times 3 \mathrm{~m}$ & 4.16 & 5.50 & 7.88 & 10.01 & 13.76 & 19.46 & 27.87 & 41.19 \\
\hline \multirow{2}{*}{$\begin{array}{l}\text { Lightscape } \\
3.2\end{array}$} & \multirow{2}{*}{ MyS } & $2 \times 1 \mathrm{~m}$. & 1.08 & 1.54 & 2.25 & 3.33 & 4.85 & 6.82 & 7.83 & 4.01 \\
\hline & & $4 \times 3 \mathrm{~m}$. & 5.50 & 7.36 & 9.70 & 13.08 & 18.28 & 24.84 & 33.50 & 43.90 \\
\hline \multirow{2}{*}{ Relux Pro } & \multirow{2}{*}{ MyS } & $2 \times 1 \mathrm{~m}$. & 1.46 & 2.08 & 2.69 & 3.01 & 2.97 & 2.73 & 2.09 & 1.45 \\
\hline & & $4 \times 3 \mathrm{~m}$ & 3.81 & 5.23 & 7.19 & 10.35 & 14.60 & 20.70 & 28.98 & 39.11 \\
\hline
\end{tabular}

Table 12: Calculation of the sky component at the study points of the models with unglazed façade opening according to lighting simulation programs.

\section{Analysis of results}

\subsection{Analysis of the sky component in the model with unglazed roof opening}

After determining the sky component in the measurement points represented in Figure 1, the relative difference of the results obtained with the lighting programs in relation to the analytical calculation for each type of sky is obtained. Consequently, the sky components calculated using the programs 3DS Max Design 2014, Daylight Visualizer 2.6, DaySim 3.1 b and Design Builder 3.0 are compared 
Analysis of the accuracy of the sky component calculation in daylighting simulation programs

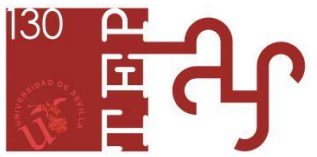

with the analytical results of the Standard Overcast Sky, while the measurements obtained using Dialux 4.8, Ecotect Analysis 201 1, Lightscape 3.2 and Relux Pro are contrasted with the analytical results of the Traditional Overcast Sky. As stated in the methodology, the results of the calculation models under standard and traditional overcast sky conditions were calculated using the CIE test cases [8] and represented in Table 1. The relative difference of all lighting programs in relation to the calculation model established in the CIE test cases, considering a $1 \times 1 \mathrm{~m}$ roof opening is observed in Figure 3.

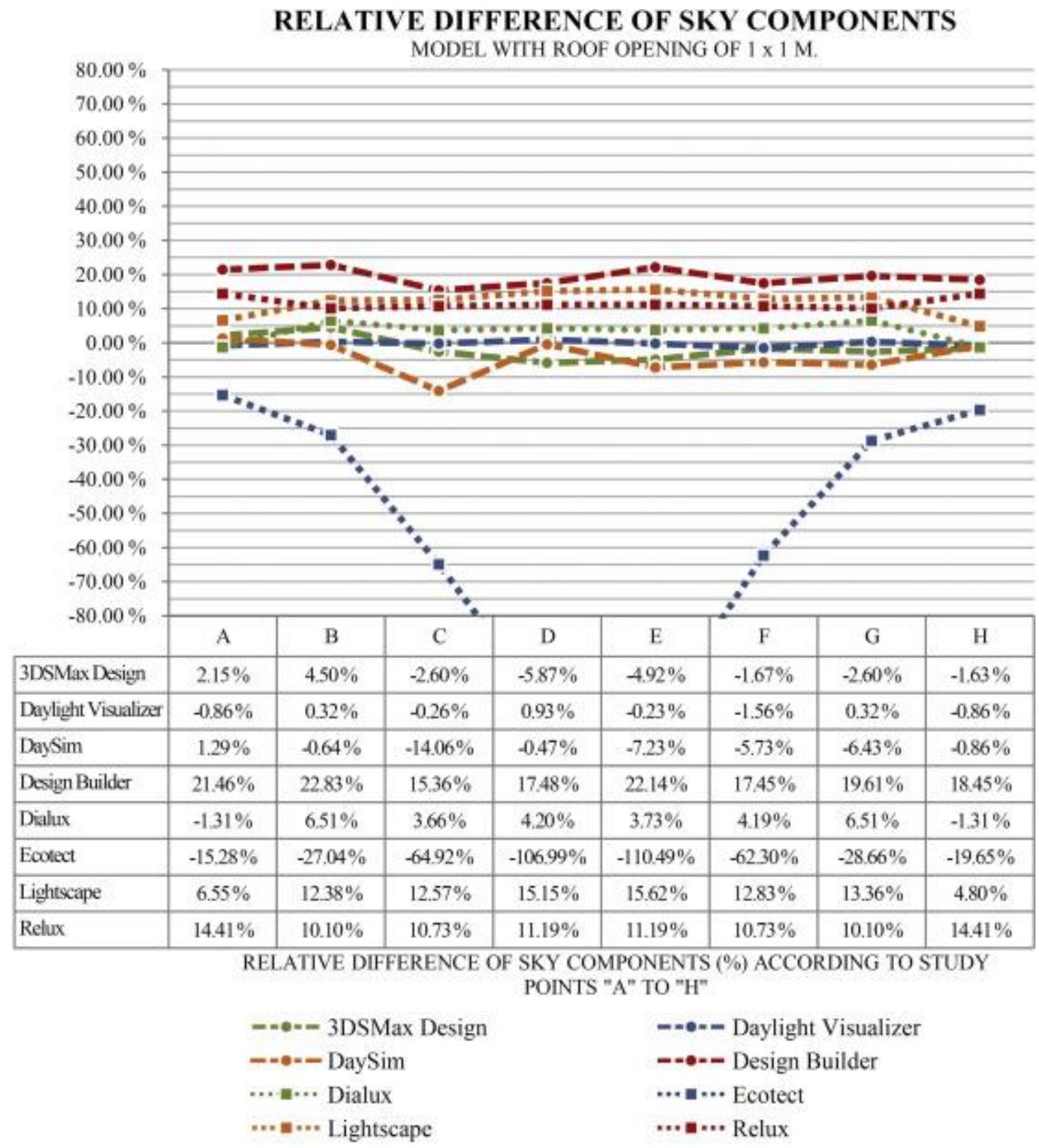

Figure 3: Relative difference of sky components of lighting programs with respect to CIE test cases. Model with unglazed roof opening of $7 \times 7 \mathrm{~m}$. 


\section{Analysis of the accuracy of the sky component calculation in daylighting simulation programs}

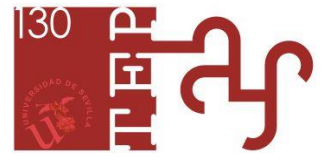

The room with a $1 \times 1 \mathrm{~m}$ roof opening is the most complex calculation model given that the sky components of the study points depend on a solid angle smaller than that of other simpler geometry models. Consequently it is consistent that the margin of error of the lighting programs should be greater in this first analysis.

As is deduced from Figure 3, the 3DS Max Design 2014, Daylight Visualizer 2.6, DaySim 3.1 b and Dialux 4.8 lighting programs maintain a relative difference with respect to the analytical calculations lower than 5.00\%, except in concrete cases. Specifically it is observed that in all cases Daylight Visualizer 2.6 produces a margin of error lower than 2.00\%, while 3DS Max Design 2014 and Dialux 4.8 elevate this margin to $6.00 \%$ approximately.

Secondly, Lightscape 3.2 and Relux Pro maintain a margin of error lower than $15.00 \%$ and a mean of about $12.00 \%$. Based on the results obtained it can be argued that the lighting programs have fair precision to calculate daylighting, although indubitably there are programs which offer greater precision than others.

Finally it is observed that the relative difference for Design Builder 3.0 increases to $23.00 \%$, although this margin of error is constant at almost all study points. The same cannot be said of Ecotect Analysis 2011 , as its margin of error varies between 15.00 and $110.00 \%$, concluding that the reliability of this program is questionable.

Figure 4 shows the relative difference of all the lighting programs in relation to all the calculation models established in CIE test cases, considering a $4 \times 4$ m roof opening. 
Analysis of the accuracy of the sky component calculation in daylighting simulation programs

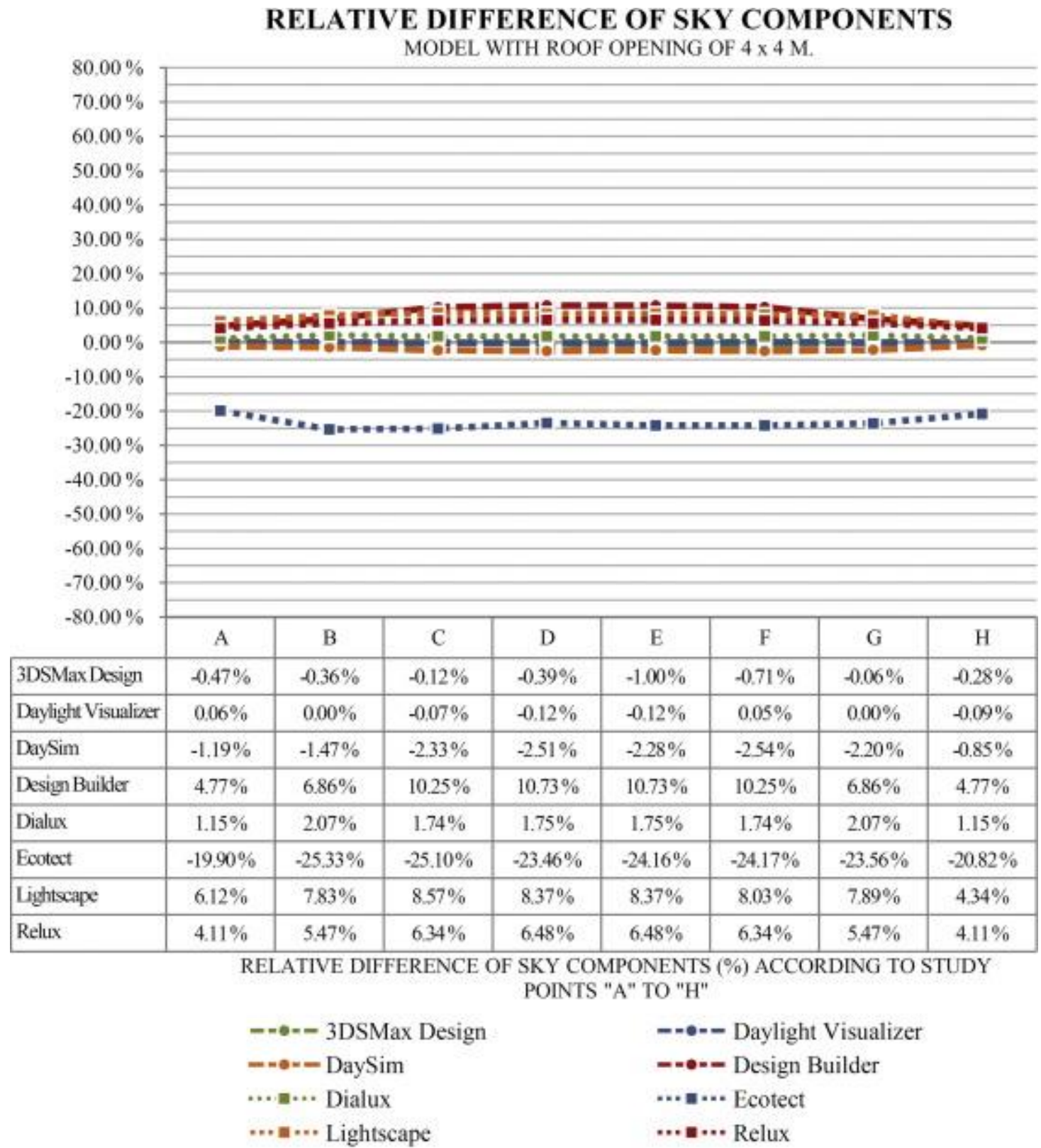

Figure 4: Relative difference of sky components of lighting programs with respect to CIE test cases. Model with unglazed roof opening of $4 \times 4 \mathrm{~m}$.

In contrast with the previous calculation model, the room with a $4 \times 4 \mathrm{~m}$ roof opening has the simplest shape for a calculation model, as the solid angle from any study point is considerably wider, and it is therefore reasonable to conclude that the margin of error is reduced considerably for all lighting programs. In this analysis, the 3DS Max Design 2014, Daylight Visualizer 2.6, DaySim 3.1 b and Dialux 4.8 lighting programs show a relative difference with respect to the analytical calculation lower than 3.00\% in all cases. It is worth noting the example of 3DS Max Design 2014 and Daylight Visualizer 2.6 where the margin of error does not exceed $1.00 \%$ in either case. 
Just as with the previous test, it is observed that the relative difference of Lightscape 3.2 and Relux Pro is fairly acceptable, showing a margin of error of about $8.00 \%$.

As regards Design Builder 3.0 it is observed that the margin of error is greatly reduced, and from what can be deduced the precision of this lighting program is conditioned by the value of the solid angle.

Unlike the rest of programs, it is observed that Ecotect Analysis 2011 results in a constant yet elevated margin of error, considering the simplicity of the calculation model.

\subsection{Analysis of the sky component in the model with unglazed façade opening}

Considering the calculation model with façade opening represented in Figure 2, the relative difference of the results obtained with the lighting programs is analyzed with respect to the analytical calculation for each type of sky. This relative difference is obtained from a comparison of the results of Table 12, the results obtained from the lighting programs, and Table 2, which shows the analytical calculation using the CIE test cases [8]. The relative difference of all the lighting programs with respect to the calculation model established in the CIE test cases, considering a $2 \times 1 \mathrm{~m}$ façade opening is shown in Figure 5. 
Analysis of the accuracy of the sky component calculation in daylighting simulation programs

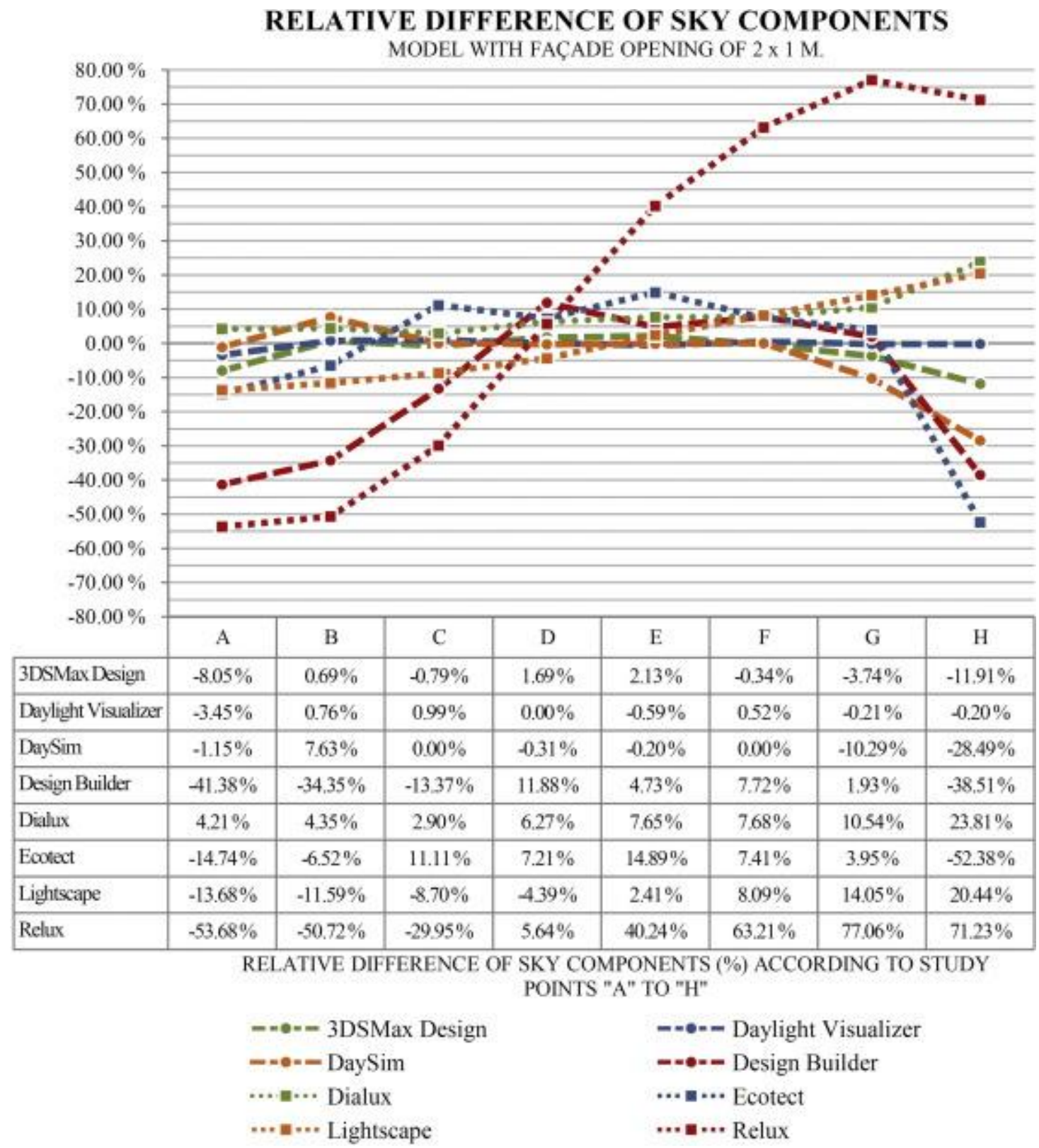

Figure 5: Relative difference of sky components of lighting programs with respect to CIE test cases. Model with unglazed façade opening of $2 \times 1 \mathrm{~m}$.

This calculation model for a room with a $2 \times 1 \mathrm{~m}$ opening in the centre of the façade is roughly as complex to calculate similar to the model with a $1 \times 1 \mathrm{~m}$ roof opening given that the solid angle measured from the study points to the opening is quite acute in the extremes of the room. Consequently, it is consistent for margin of error of the lighting programs to be higher at points " $A$ " and " $\mathrm{H}$ ".

In this analysis, Daylight Visualizer 2.6 is notably precise, showing an average margin of error of about $1.00 \%$ and in all cases lower than $4.00 \%$, even at extremes, where the solid angle is smaller and in consequence the margin of error tends to be higher. 
Analysis of the accuracy of the sky component calculation in daylighting simulation programs

In contrast, 3DS Max Design 2014, DaySim 3.1b and Dialux 4.8 show an average margin of error lower than $10.00 \%$, although this margin is noticeably higher at study points in the extremes of the room.

It is observed that Lightscape 3.2 offers acceptable results, showing an average relative difference of about $10.00 \%$ and lower than $20.00 \%$ in all cases.

Finally, and considering the calculation model with façade opening it is observed in all cases that the results from Design Builder 3.0, Ecotect Analysis 2011 and Relux Pro are notably questionable.

Figure 6 below shows the relative difference of all lighting programs in relation to the analytical calculation model established in CIE test cases, considering a $4 \times 3 \mathrm{~m}$ façade opening.

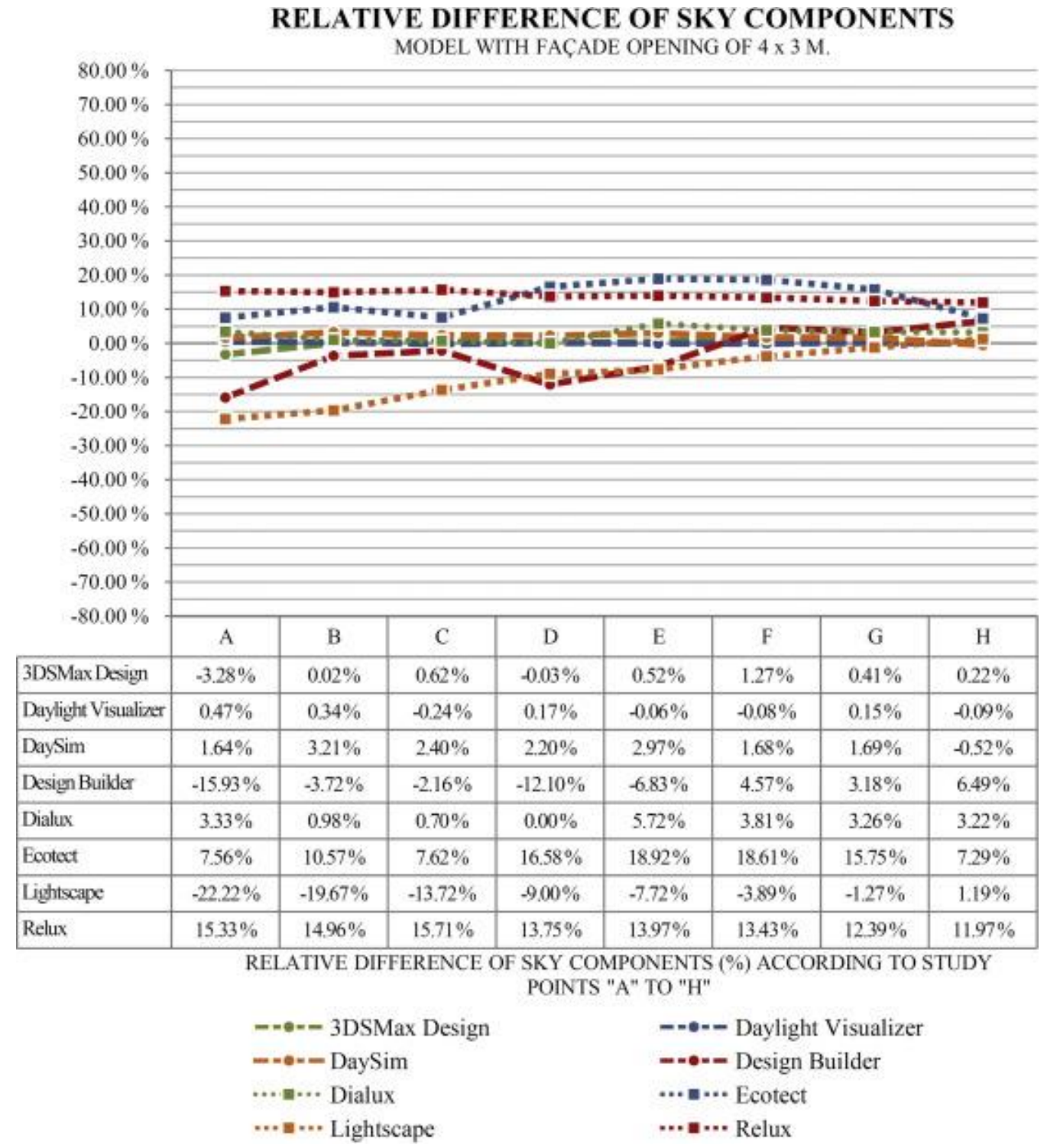

Figure 6: Relative difference of sky components of lighting programs with respect to CIE test cases. Model with unglazed façade opening of $4 \times 3 \mathrm{~m}$. 


\section{Analysis of the accuracy of the sky component calculation in daylighting simulation programs}

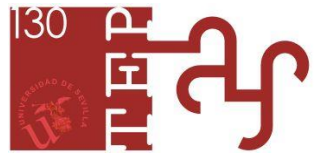

Just as with the second model with roof opening, the room with the $4 \times 3$ m façade opening has a simple shape, permitting a solid angle that is fairly wide from all study points, as well as a relative difference in relation to the notably reduced analytical calculation. In fact, the highest margin of error is observed in point " $\mathrm{A}$ ", where the solid angle is smaller, while the lighting programs tend to converge at point " $\mathrm{H}$ ", close to the opening that covers the entire surface of the façade.

After carrying out an in-depth analysis of the results it can be observed that 3DS Max Design 2014, Daylight Visualizer 2.6, DaySim 3.1 b and Dialux 4.8 programs show a relative difference with respect to the analytical calculation lower than $4.00 \%$ in all cases. In fact, the margin of error of Daylight Visualizer 2.6 is lower than $0.50 \%$.

In the analysis of Design Builder 3.0 and Lightscape 3.2 it is observed that the margin of error is acceptable at the study points near the opening, although this margin is higher in the further away points. From this it is concluded that both programs are affected by the geometrical complexity of the model, although Lightscape 3.2 shows more noticeably solid results.

Finally, both Ecotect Analysis 2011 and Relux Pro show an acceptable margin of error for this calculation model, lower than $20.00 \%$ in all cases, although it is observed that this margin is not subject to the variations of the solid angle measured from the study points to the opening.

\section{Conclusion}

Following the calculation of the sky components of each lighting simulation program, represented in Tables 11 and 12, as well as its comparison with the analytical calculation through Tregenza algorithms [27] and the CIE test cases [8] represented in Tables 1 and 2, the precision of each program can be concluding depending on the method.

Although 3DS Max Design 2014 is a program used mostly for commercial use, the results obtained in contrast with the sky component show considerable precision in almost all calculations. It is observed that the maximum relative divergence with relation to the analytical calculation is below $12.00 \%$ in the more complex models and below $4.00 \%$ in models with larger openings. It is concluded that the reliability of the program is suited to all the study points, showing an average margin of error lower than $4.00 \%$. This margin is reduced below $1.00 \%$ when the room opening is large and the solid angle is, in turn, correspondingly wide.

Daylight Visualizer 2.6 is one of the most up-to-date programs specifically dedicated to daylighting calculation. Its precision is attested to by the tests executed, which show a maximum relative difference with respect to the CIE test cases of less than $4.00 \%$ in the more complex models and lower than $1.00 \%$ in large openings in a room. The average margin of error is below $1.00 \%$ for all 


\section{Analysis of the accuracy of the sky component calculation in daylighting simulation programs}

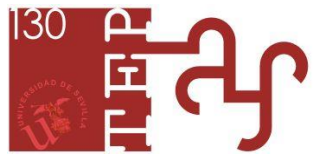

case studies, so it is concluded that this lighting program is a point of reference in the calculation of the sky component.

Based on the Radiance calculation software, the DaySim 3.1b program represents evolution in lighting simulation programs. The average margin of error of this program is very acceptable, lower than $6.00 \%$ in the more complex models and lower than $2.00 \%$ in rooms with smaller openings. In very specific cases with narrow solid angles, the relative divergence with respect to the analytical calculation can be increased on occasion. However, it can be stated that, except on the odd occasion, the precision of this program is high.

Design Builder 3.0 is based on EnergyPlus daylighting calculation, and also enables the analysis of thermal comfort and other parameters linked to buildings. In this program, the average margin of error reaches $14.00 \%$, although this value reaches $40.00 \%$ at certain study points in the calculation models. As is deduced from Figures 5 and 6, Design Builder 3.0 offers a precise calculation of the sky component at points where the solid angle is sufficient, with a considerable divergence of the analytical calculation at the extremes, where the opening is less visible and sky component is smaller. It is therefore concluded that this program facilitates an approximate calculation of the sky component, although it tends to diverge when the geometry is complex.

Dialux 4.8 was created as a program for the calculation of artificial lighting, and therefore it is surprising that the calculation of the sky component should provide acceptable results. The average margin of error with respect to the analytical calculation is below $10.00 \%$ in models with a complex geometry and lower than $3.00 \%$ in rooms with large openings. However, this margin is above $20.00 \%$ at study points associated with a reduced solid angle. Nevertheless, it can be stated that Dialux 4.8 is a program of acceptable precision, despite its limitations.

As is the case of Design Builder 3.0, Ecotect Analysis 2011 allows a wide range of simulations associated with energy efficiency in buildings. However, in the tests executed in this research it is clear that the results of the program are questionable. In the case of the model with a roof opening, the average relative difference with respect to the analytical calculation exceeds $20.00 \%$ in the model with a $4 \times 4$ m opening and exceeds $50.00 \%$ in the room with a $1 \times 1 \mathrm{~m}$ opening. In the case of the façade opening model the average margin of error decreases to $15.00 \%$, although at some study points this margin exceeds $50.00 \%$. As a result, it can be concluded that the precision of this program in the calculation of the sky component is questionable.

In the case of Lightscape 3.2 the results obtained in the contrast of the sky component show acceptable precision in most study points. It is observed that the average relative difference with respect to the analytical calculation is lower than $15.00 \%$ in the more complex models and lower 


\section{Analysis of the accuracy of the sky component calculation in daylighting simulation programs}

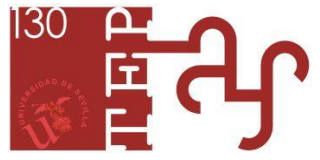

than $10.00 \%$ in models with larger openings. At certain study points, with smaller solid angles, the margin of error increases and so it is deduced that precision is reduced in the case of complex geometries.

Finally, the Relux Pro program shows acceptable precision in models with roof opening, resulting in a margin of error lower than $12.00 \%$ and a maximum divergence with respect to the analytical calculation of about $14.00 \%$, confirming the reliability of the program in this calculation model and the uniformity of its results. However, in the case of the models with façade opening, the average margin of error increases to $50.00 \%$ in the $2 \times 1 \mathrm{~m}$ opening model, so it can be concluded that the precision of this program is questionable when evaluating the sky component through windows.

\section{References}

[1] D.I. Ibarra, C.F. Reinhart, Daylight factor simulations - How close do simulation begginner 'really' get? Glasgow, Scotland: Proceedings of 11 th International IBPSA Conference (2009), 196-203.

[2] I.E.A. S.H.C., Daylighting Buildings in the 21 st Century. Application of the CIE test cases to assess the accuracy of lighting computer programs, I.E.A. S.H.C. Report, Task 31 (2005).

[3] C.E. Ochoa, M.B.C. Aries, J.L.M., Hensen, State of the Art in Lighting Simulation for Building Science: A literatura Review, Journal of Building Performance Simulation 5(2012), 209-233.

[4] J.M. Estes, S. Schreppler, T. Newsom, Daylighting prediction software: comparative analysis and application. Tyler, Texas, USA: Proceedings of 14th Symposium on Improving Building Systems in Hot and Humid Climates (2004), 259-267.

[5] X. Shi, W. Yang, Performance-driven architectural design and oprimization technique from a perspective of architects, Automation in Construction 32 (2013), 125-135.

[6] S. Kota, J.S. Haberl, Historical survey of daylighting calculations methods and their use in energy performance simulations. Austin, Texas, USA: 9th International Conference for Enhanced Building Operations (2009).

[7] F. Maamari, M. Fontoynont, Analytical tests for investigating the accuracy of lighting programs, Lighting Research and Technology 35(3) (2003) 225-242.

[8] CIE, Test cases to assess the accuracy of lighting computer programs, Commission Internationale de l'Éclairage (2006). CIE 171:2006.

[9] C.F. Reinhart, P.F. Breton, Experimental validation of Autodesk (r) 3Ds Max (r) Design 2009 and Daysim 3.0, Leukos 6(1) (2009) 7-35. 
[10] A. Iversen, N. Roy, M. Hvass, M. Jørgensen, J. Christoffersen, W. Osterhaus, K. Johnsen, Daylight Calculations in Practice: An investigation of the ability of nine daylight simulation programs to calculate the daylight factor in five typical rooms. . Danish Building Research Institute (2013).

[11] C.F. Reinhart, A. Fitz, Findings from a survey on the current use of daylight simulations in building design, Energy and Buildings 38 (2006) 824-835.

[12] Lawrence Berkley National Laboratory, EnergyPlus Engineering Reference. The reference to EnergyPlus Calculations, Lawrence Berkeley National Laboratory, Technical report (2012) 1278.

[13] G. Yun, K.S. Kim, An empirical validation of lighting energy consumption using the integrated simulation method, Energy and Buildings 57 (2013) 144-154.

[14] G. Ramos, E. Ghisi, Analysis of daylight calculated using the EnergyPlus programme, Renewable and Sustainable Energy Reviews 14 (2010) 1948-1958.

[15] J. Mardalievic, Verification of program accuracy for illuminance modelling: assumptions, methodoogy and an examination of conflicting findings, Lighting Research and Technology 36(3) (2004) 217-242.

[16] M.S. Ubbelohde, C. Humman, Comparative evaluation of four daylighting software programs. Berkeley, CA, USA: ACEEE, 1999. Proceedings of the 1998 Summer Study on Energy Efficiency in Buildings, 3325-3340.

[17] J. Ashmore, P. Richens, Computer simulation in daylight design: a comparison, Architectural Science Review 44 (2001) 33-44.

[18] I. Acosta, J. Navarro, J.J. Sendra, Towards an Analysis of Daylighting Simulation Software, Energies 4(7) (2011) 1010- 1024.

[19] A.D. Galasiu, M.R. Atif, Applicability of daylighting computer modeling in real case studies: comparison between measured and simulated daylight availability and lighting consumption, Building and Environment 37(4) (2002) 363-377.

[20] E. Ng, A study of the Accuracy of Daylighting Simulation of Heavily obstructed Buildings in Hong Kong. Rio de Janeiro, Brazil : IBPSA, 2001. Proceedings of Building Simulation 2001 Conference, 1215-1222.

[21] C.E. Ochoa, I.G. Capeluto, Evaluating visual comfort and performance of three natural lighting systems for deep office buildings in highly luminous climates, Building and Environment 41 (2006) 1128-1135. 
[22] C.S. Kim, S.J. Chung, Daylighting simulation as an architectural design process in museums installed with toplights, Building and Environment 46 (2011) 210-222.

[23] J. Mardaljevic, Validation of a lighting simulation program under real sky conditions, Lighting Research and Technology 27(4) (1995) 181-188.

[24] E.A. Kopylov, A.B. Khodulev, V.L. Volevich, A. Physically Accurate Lighting Simulation in Computer Graphics Software, Keldysh Institute of Applied Mathematics (1996).

[25] J. Mardaljevic, The BRE-IDMP dataset: a new benchamark for the validation of illuminance predictions techniques, Lighting Research and Technology 33(2) (2001) 117-134.

[26] M. Fontoynont, I.E.A. S.H.C., Validation of daylighting computer programs, I.E.A. S.H.C. Report, Task 21 (1999).

[27] P. Tregenza, Daylighting algorithms. ETSU S 1350, U.K. Department of Trade and Industry on behalf of the Energy Technology Support Unit (1993) 43.

[28] CIE, Spatial Distribution of Daylight - CIE Standard General Sky, Commission Internationale de I'Éclairage (2003). CIE S 011 1/E :2003.

[29] P. Moon, D.E. Spencer, Illumination from a Non-Uniform Sky. Illuminating Engineering 37 (1942) 707-726.

[30] R. Perez, R. Seals, J. Michalsky, All-Weather Model for Sky Luminance Distribution - Preliminary Configuration and Validation, Solar Energy 50 (3) (1993) 235-245. 